\title{
Studies on Leaf Surface Lipid of Tobacco III. Compositional Change in Alkane during Growth and Senescence of Tobacco Leaves
}

\author{
Kenji Gamou and Nobumaro KaWASHIMA \\ Utsunomiya Tobacco Experiment Station, The Japan Tobacco \& Salt Public Corporation, \\ 1900 Idei, Oyama, Tochigi 323, Japan \\ Received March 17, 1980
}

\begin{abstract}
Alkane is the major constituent of epicuticular wax universally distributed in plants. Tobacco leaves contained $5 \sim 10 \mathrm{mg}$ of alkane per $1000 \mathrm{~cm}^{2}$. The content gradually increased with leaf age. Leaves on the upper stalk contained more alkane than those on lower stalk. Components with carbon numbers from 27 to 33 occupied more than $98 \%$ of the total alkane content. In relative ratios of alkane components, anteiso- $\mathrm{C}_{30}$ and normal- $\mathrm{C}_{31}$ were most drastically and increased, respectively, with leaf age regardless of stalk position. On the other hand, normal- $\mathrm{C}_{29}$ and normal- $\mathrm{C}_{33}$ increased and decreased, respectively, from the upper to lower stalk positions without being affected by leaf age. These results suggest the possible use of alkane composition as an index of leaf maturity and stalk position, for example, the ratio of anteiso- $C_{30} /$ normal- $C_{51}$ for maturity and normal- $C_{38} /$ normal $-C_{29}$ for stalk position.
\end{abstract}

In a plant, a surface which is exposed to the atmosphere usually has a layer which contains wax and is called the cuticle. The wax may help preserve the water balance of the plant, and its other protective functions may include minimizing mechanical damage to leaf cells and inhibiting fungal and insect attack.

The wax especially in the outermost layer, epicuticular, generally consists of long chain alkanes, alcohols, acids, wax esters and terpenoids. ${ }^{1)}$ Above all, alkanes are known to be the constituents of the wax universally distributed among plants. Troughton and $\mathrm{Hall}^{2}$ reported that the electron microscopic appearance of the wax layer of wheat leaves varied with the stage of growth. More recently, Bukovac et $a l^{3}{ }^{3}$ reported changes in ultrastructure of the leaf surface, with a concomitant increase of alkane content, during leaf growth.

In regard to alkane composition, Tulloch with wheat leaves," Stocker and Wanner with coffee leaves ${ }^{\text {) }}$ and Baker et al. with peach leaves $^{\theta)}$ individually reported that a compositional change in $\mathrm{C}_{23}$ to $\mathrm{C}_{33}$ alkanes occurs during the leaf growth. In tobacco, although not so extensive studies as above mentioned have been conducted, Chang and Grunwald ${ }^{\text {) }}$ showed little compositional differences of normal series alkanes among the leaves from different stalk positions and between the leaves of 10 and 14 weeks after transplantation. After harvesting the leaves, as reported by Carruthers and Johnstone, ${ }^{81}$ components of tobacco alkanes do not vary significantly during fermentation of the leaves, or even after converting the alkanes into tar by smoking. Because of this situation, we planned more precise studies on compositional changes in alkanes during growth and senescence of tobacco leaves, to find a chemical marker of leaf maturity which is now only determined by the farmers' experience, since leaf quality of commercial tobacco greatly depends upon the maturity at harvesting time.

\section{MATERIALS AND METHODS}

Plants. The most popular cultivars of Nicotiana tabacum in Japan, MC and Shiroenshu, were grown in a field of the Utsunomiya Tobacco Experiment Station in 1979. Nutrients were supplied in the conventional manner ( $\mathrm{N}: \mathrm{K}: \mathrm{P}, 0.9: 2.6: 2.7 \mathrm{~kg} / \mathrm{a}$ for $\mathrm{MC}$, $1.2: 2.9: 2.5 \mathrm{~kg} / \mathrm{a}$ for Shiroenshu) unless otherwise indicated. Sampling was started at about 1 month after 
transplantation, and then leaves were taken every two weeks, sometimes with a few days delay due to weather, from 4 stalk positions, $11 \sim 12$ th, 16 17th, $21 \sim 22$ nd and $26 \sim 27$ th after the cotyledon. In the case of alkane determination, 10 plants per sampling were enough to eliminate irregularity of plants in the field.

Extraction and separation of alkane. 20 leaves from each of 10 plants were separated into two down the midrib. A half of them was weighed, the area measured and the leaf surface lipid extracted with chloroform according to a previous report. ${ }^{9}$ The chloroform extract was concentrated to $20 \mathrm{ml}$. For separation of alkane, $2 \mathrm{ml}$ of the extract was applied on a $1 \times 25 \mathrm{~cm}$ silica gel column (Wako gel C-200). The column was eluted with $n$-hexane, and alkane passed through in the first $20 \mathrm{ml}$. The alkane fraction was kept in a refrigerator, after concentration to $2 \mathrm{ml}$, until use.

Analysis of alkane content and composition. Alkane content and the relative content of each component were analyzed by GLC on a $3 \mathrm{~m}$ column of $1 \%$ OV 101 (120 140 mesh Gas Chrom Q) with a computer for area determination. Injection port and detector temperatures were $300^{\circ} \mathrm{C}$ and the column was programmed from 180 to $280^{\circ} \mathrm{C}$ at $6^{\circ} \mathrm{C} / \mathrm{min}$. Carrier gas was $\mathrm{N}_{2}$ and flow rate was $70 \mathrm{ml} / \mathrm{min}$. Each peak separated was identified by GC-MS.

\section{RESULTS}

In this experiment, we used two different kinds of tobacco, a flue-cured type tobacco (MC) and an air-cured type tobacco (Shiroenshu). Usually, flue-cured type tobaccos grow smaller but produce stiffer leaves than the aircured types. In terms of chemical constituents, leaves of the flue-cured type tobacco contain much larger amounts of carbohydrate than those of the air-cured type tobaccos. Using these leaves, changes in alkane content during growth and senescence of the leaves were determined. Alkane contents per unit leaf area for both leaves were similar, 5 to $10 \mathrm{mg}$ per $1000 \mathrm{~cm}^{2}$, as shown in Fig. 1. Figure 1 also shows that alkane content gradually increased with leaf age. As also reported by Chang and Grunwald, ${ }^{7}$ our results, which are shown in Fig. 2 as a typical

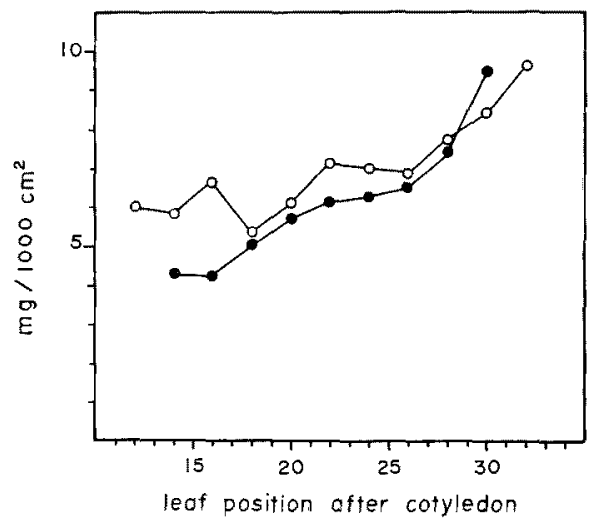

FIG. 2. Alkane Content of Tobacco Leaves at Difierent Stalk Positions at the Flowering Time.

$\mathrm{MC} ; \mathrm{O}-\mathrm{O}$, Shiroenshu.

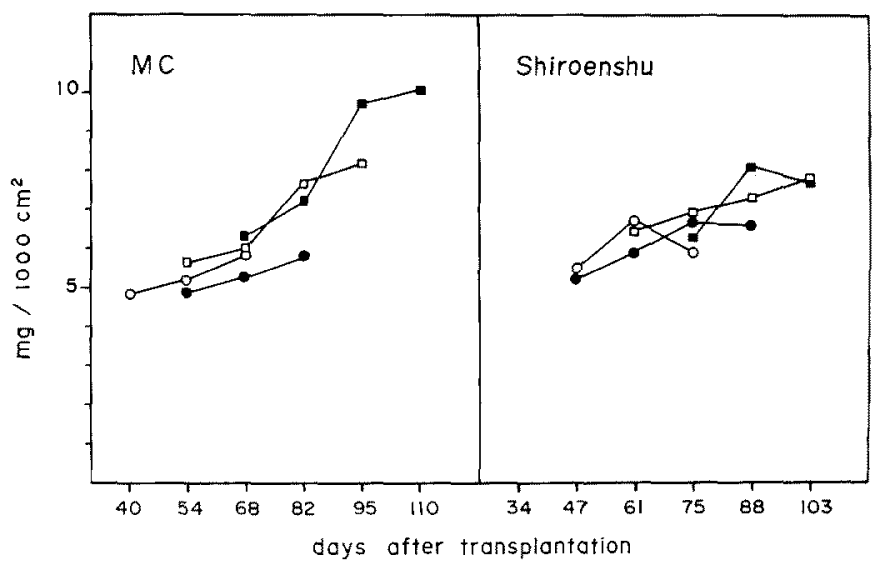

FIG. 1. Changes in Alkane Content during Growth and Senescence of Tobacco Leaves.

$0-0,11 \sim 12$ th leaves; --, $16 \sim 17$ th leaves; $\square-\square, 21 \sim 22$ nd leaves; $\mathbf{m}-\mathbf{m}, 26 \sim 27$ th leaves after the cotyledon. 
example determined at the flowering time, indicated that leaves of upper stalk positions tent to contain more alkane than those of lower stalk positions. Besides, there were no essential variety difference in alkane content between the two cultivars. Using the above mentioned two cultivars, compositional changes in alkane components during growth and senescence of the leaves were studied.

The most common paraffins of plant cuticular waxes are normal alkanes ranging in carbon number from 27 to 33. However, some plants have a substantial proportion of branched alkanes. A typical example is tobacco leaves which contain iso and anteiso homologue alkanes in very high concentrations, accounting for 40 to $50 \%$ of the total alkane mixture. ${ }^{10)}$ In the present experiments, it was found that as much as $60 \%$ of alkanes in the young upper leaves consisted of iso (2-methyl) and anteiso (3-methyl) series. The relative

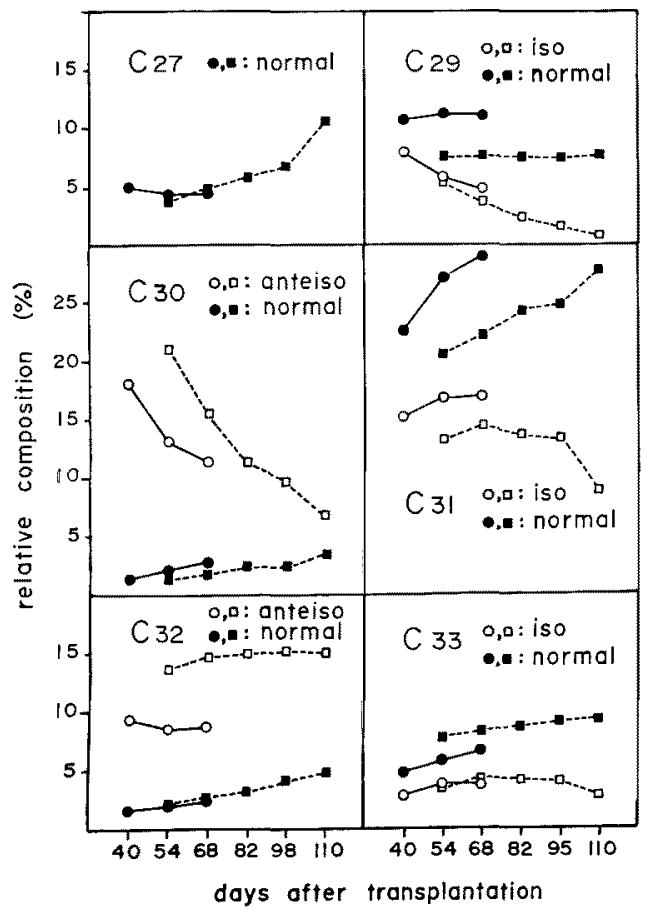

FIG. 3. Relative Composition of Respective Alkane Components to Total Alkane with Leaf Age of a Flue-cured Type Tobacco, " $M C$ ".

- $11 \sim 12$ th leaves; --..-., $21 \sim 22$ nd leaves after cotyledon. content of normal series increased up to $70 \%$ when leaves became older.

Figure 3 shows changes in relative contents of respective alkane components with leaf age of a flue-cured type tobacco (MC). The components indicated in this figure, that is from $\mathrm{C}_{27}$ to $\mathrm{C}_{33}$, always occupied more than $98 \%$ of the total alkane content. Relative content of normal- $\mathrm{C}_{27}$, normal- $\mathrm{C}_{30}$, normal- $\mathrm{C}_{31}$ and normal- $_{32}$ successively increased with leaf age. The levels of normal- $\mathrm{C}_{29}$, anteiso- $\mathrm{C}_{32}$, normal$\mathrm{C}_{32}$ and iso- $\mathrm{C}_{33}$ remained constant. On the other hand, anteiso- $\mathrm{C}_{30}$ and iso- $\mathrm{C}_{29}$ drastically decreased with leaf age. Similar results were obtained when alkanes of an air-cured type tobacco (Shiroenshu) was examined. The results are shown in Fig. 4.

Now, the question arises as how the decrement of relative content of anteiso- $\mathrm{C}_{30}$ happened. From the calculation of alkane content on the basis of a piece of leaf, a young

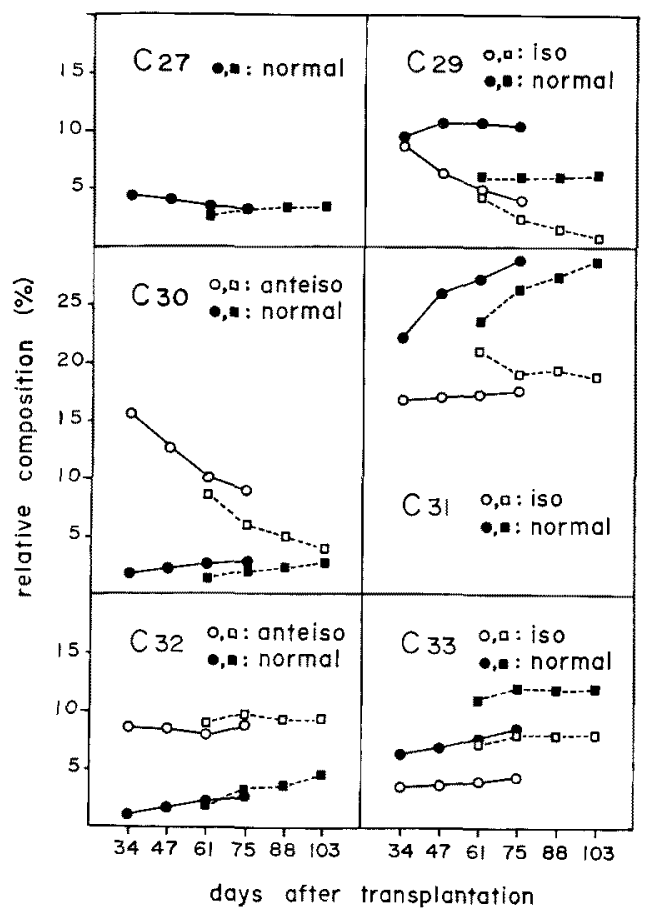

FIG. 4. Relative Composition of Respective Alkane Components to Total Alkane with Leaf Age of an Air-cured type Tobacco, "Shiroenshu".

$\ldots, 11 \sim 12$ th leaves; -...--, $21 \sim 22$ nd leaves after cotyledon. 
$21 \sim 22$ nd leaf at a plant age of 54 days after transplantation contained at total of $37 \mathrm{mg}$ alkane and $7.7 \mathrm{mg}$ of anteiso- $\mathrm{C}_{30}$. During the 41 days thereafter, the total alkane content increased to $90 \mathrm{mg}$ in contrast to an only slight increase of anteiso- $\mathrm{C}_{30}$ to $8.5 \mathrm{mg}$. The results show that most of the anteiso- $C_{30}$ had already been accumulated in the leaves before the time at the plant age of 54 days, when the leaf size was about half of the fully expanded state, and thereafter synthesis of this alkane component was greatly retarded. Actually, we have examined much younger and smaller leaves in another experiment and found that more than $30 \%$ of the total alkane consisted of anteiso$\mathrm{C}_{30}$. This result may support the above hypothesis that anteiso- $\mathrm{C}_{30}$ is only actively synthesized in the leaves at a very young stage.

One purpose of the experiment was to see whether leaf maturity can be estimated by detecting the relative contents of the alkane components. For this purpose, we used the ratio of anteiso- $\mathrm{C}_{30}$ to normal- $\mathrm{C}_{31}$, which were the most drastically decreased and increased components, respectively, with age, as an index for maturity estimation. To obtain leaves of different maturity but of the same age, tobacco plants were grown under two nitrogen fertilizer levels, 0.9 and $1.3 \mathrm{~kg} / \mathrm{a}$. Although both $22 \mathrm{nd}$ leaves started to develop at the same time, the leaves with the $1.3 \mathrm{~kg}$ nitrogen condition always seemed to be more colored and were estimated to be less mature by experience than those with the $0.9 \mathrm{~kg}$ nitrogen condition. As shown in Fig. 5, the ratio of anteiso- $\mathrm{C}_{30}$ / normal- $\mathrm{C}_{31}$ of the leaves with the $1.3 \mathrm{~kg}$ nitrogen condition always exceeded the ratio with the $0.9 \mathrm{~kg}$ nitrogen condition, comparing leaves of the same plant age. These results may show that there is some correlation between the degree of maturity and the ratio of anteiso$\mathrm{C}_{30}$ /normal- $\mathrm{C}_{31}$, indicating the possible use of the ratio as an index of leaf maturity.

The data of Figs. 3 and 4 show that there are some alkane components of which the relative contents are significantly different between leaves from upper and lower stalk positions. The results imply that the leaves

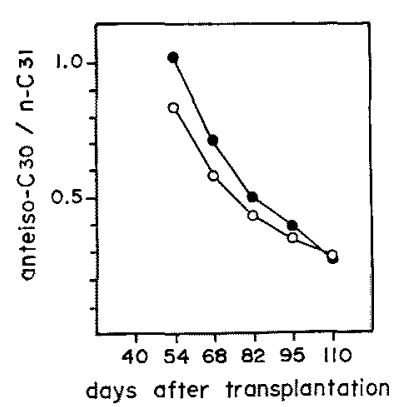

FIG. 5. The Ratio of anteiso- $\mathrm{C}_{30} /$ normal- $\mathrm{C}_{31}$ of Tobacco Leaves under Different Nitrogen Fertilizer Levels, 0.9 and $1.3 \mathrm{~kg} / \mathrm{a}$.

$\bigcirc-0,0.9 \mathrm{~kg} / \mathrm{a} ;-0,1.3 \mathrm{~kg} / \mathrm{a}$.

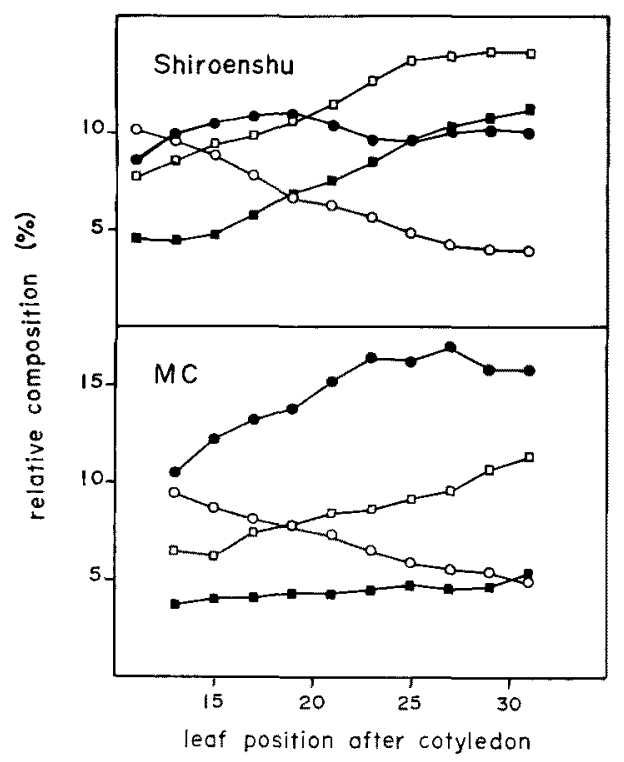

FIG. 6. Relative Composition of Respective Alkane Components to Total Alkane of Tobacco Leaves at Different Stalk Positions at the Flowering Time.

$\mathrm{O}-\mathrm{O}$, normal- $\mathrm{C}_{28} ;-\longrightarrow$, anteiso- $\mathrm{C}_{32} ; \square-\square$, normal$\mathrm{C}_{33} ; \mathbf{E}-\mathbf{n}$, iso- $\mathrm{C}_{39}$.

of respective stalk positions have their own characteristic features in regard to respective contents of alkane components. To ascertain the above phenomena, the relative contents of normal- $\mathrm{C}_{29}$, anteiso- $\mathrm{C}_{32}$, normal- $\mathrm{C}_{33}$ and iso$\mathrm{C}_{33}$ of the leaves from different stalk positions at the flowering time were analyzed, since the relative contents of these components to the total alkane were not affected by the age of the leaves (Figs. 3 and 4). The results are 
shown in Fig. 6. Relative contents of normal$\mathrm{C}_{29}$ and normal- $\mathrm{C}_{33}$ were the most characteristic for stalk position, the former increased and the latter decreased from the upper to the lower leaf positions. This tendency was also observed when an additional two air-cured type cultivars (Matsukawa and Daruma) were examined. This character of stalk position could be more clearly expressed using the ratio of normal- $\mathrm{C}_{33} /$ normal- $\mathrm{C}_{29}$ as an index. Using this index, it may be possible to identify the stalk positions from which the leaves-came, and to identify the stalk position of stray leaves as is often necessary in the tobacco industry.

\section{DISCUSSION}

Long chain hydrocarbons are universally distributed in plants and animals. Nevertheless, the exact mechanism by which these compounds are formed is not yet clear. Based on the experimental results using various labeled precursors of alkanes, Kolattukudy's group $^{11)}$ proposed a probable mechanism for biosynthesis of normal alkanes. Their hypothesis was that an enzyme complex successively adds $\mathrm{C}_{2}$ units to a preformed fatty acid substrate $\left(\mathrm{C}_{16}\right)$ until the appropriate chain length is reached, and then the long fatty acid undergoes decarboxylation and reduction to the corresponding alkane. If this is the case, it is easy to understand why the majority of normal series of alkanes are distributed in components with odd numbered carbon skeletons. However, our experimental results as well as others $^{10,121}$ show that an appreciable amount $(3 \sim 7 \%$ ) of normal alkanes with even numbered carbon skeletons are distributed in the constituents. The results may imply the participation of odd numbered fatty acids in alkane synthesis, or that another mechanism is concerned. This is a problem to be solved in the future. Since tobacco is one of the plants which contain a relatively large amount of the even numbered normal alkanes, ${ }^{10,12)}$ this material must be useful for such kinds of experiments.

Another point of interest is as to how the branched alkane constituents are formed, since $N$. tabacum is a species which contains branched alkane constituents in unusually high concentrations. Kolattukudy ${ }^{11)}$ indicated that, in tobacco leaves, isoleucine- $\mathrm{U}_{-1}^{14} \mathrm{C}$ gave labeled even numbered alkanes such as anteiso$\mathrm{C}_{30}$ and $\mathrm{C}_{32}$, whereas valine- $\mathrm{U}_{-14}{ }^{14} \mathrm{C}$ gave labeled odd numbered alkanes such as iso- $\mathrm{C}_{29}, \mathrm{C}_{31}$ and $\mathrm{C}_{33}$. From the results and the elongationdecarboxylation mechanism of normal alkanes, he proposed the hypothesis that branched amino acids give rise to branched starter chains for the synthesis of branched fatty acids, which in turn produce branched alkanes by the elongation-decarboxylation mechanism. Actually, the iso and anteiso series were only distributed in even and odd numbered alkane constituents, respectively. In the same leaves used for the experiments, it was found that the isoleucine content decreased drastically with age, while the valine content decreased slightly. This phenomenum may reflect the changes in alkane constituents with age, where anteiso homologues were drastically decreased and iso homologues only slightly decreased. If this is the case, valine and isoleucine contents may be factors controlling the corresponding branched alkane synthesis. On the other hand, the present experiment showed that anteiso- $C_{30}$ is synthesized only in young leaves, whereas anteiso- $\mathrm{C}_{32}$ is synthesized regardless of the leaf age. A similar situation was observed for the iso series, where iso- $\mathrm{C}_{29}$ may be positively synthesized in only young leaves, whereas the larger iso series components, such as iso- $\mathrm{C}_{31}$ and $\mathrm{C}_{33}$, are synthesized in both young and aged leaves. Such different production of the branched constituents between young and aged leaves cannot be elucidated only the contents of the branched amino acid precursors. This may be a useful phenomenum for considering the regulation mechanism of branched alkane biosynthesis, and we are doing studies in this direction.

\section{REFERENCES}

1) G. Eglinton and R. J. Hamilton, Science, 156, 
1322 (1967).

2) J. H. Troughton and D. M. Hall, Aust. J. Biol. Sci., 20, 509 (1967).

3) M. J. Bukovac, J. A. Flore and E. A. Baker, J. Amer. Soc. Hort. Sci., 104, 611 (1979).

4) A. P. Tulloch, Phytochem., 12, 2225 (1973).

5) H. Stocker and H. Wanner, Phytochem., 14, 1919 (1975).

6) E. A. Baker, M. J. Bukovac and J. A. Flore, Phytochem., 18, 781 (1979).

7) S. Y. Chang and C. Grunwald, Phytochem., 15,
961 (1976).

8) W. Carruthers and R. A. W. Johnstone, Nature, 184, 1131 (1959).

9) K. Gamou and N. Kawashima, Agric. Biol. Chem., 43, 2163 (1979).

10) J. D. Mold, R. K. Stevens, R. E. Means and J. M. Ruth, Biochemistry, 2, 605 (1963).

11) P. E. Kolattukudy, Ann. Rev. Plant Physiol., 21, 163 (1970).

12) G. Eglinton, A. G. Gonzalez, R. J. Hamilton and R. A. Raphael, Phytochem., 1, 89 (1962). 